\title{
FISCAL DEFICITS AND INFLATION IN THE TRANSITION COUNTRIES
}

\author{
Vratislav IZÁK*
}

\begin{abstract}
:
The fiscal deficits in the majority of transition countries continue to deteriorate and pose risks for the sustainability of public finances in the longer time horizon. Due to short time span and data limitation (1993 - 2003) I concentrate on the short-run dynamics using fixed-effect model with panel data. I found a very small effects of fiscal deficits on inflation for the group of Visegrad countries (the Czech Republic, Hungary, Poland, Slovakia) with slightly better results after the exclusion of Poland. The perspective of adopting the euro in the horizon of several years has prevented until now the use of surprise inflation to reduce the real burden of servicing the increasing public debt. In the periods of social conflicts which are likely to characterize times of delayed fiscal reforms the temptation to resort to seignorage may become more stronger than nowadays.
\end{abstract}

Keywords: fiscal deficits, inflation, transition countries

JEL Classification: E31, E60, E63

\section{Introduction}

According to one of the most quoted sentences in the economic literature inflation is always and everywhere a monetary phenomenon. The following question is: "What drives money growth?" The usual answer is that the culprits are fiscal deficits, at least in high inflation countries.

The research in the last years shows that the fiscal deficit-inflation relationship is intrinsically dynamic. Under fiscal dominance, deficits determine the present value of seignorage but not necessarily current seignorage. This is because borrowing

*) University of Economics, 4, W. Churchill Sq., CZ - 13067 Prague 3 (e-mail: izak@ vse.cz).

$\left.{ }^{* *}\right)$ The paper is a part of the research grant of the Grant Agency of the Czech Republic No.402/03/1227 and was presented at the 60th Congress of the International Institute of Public Finance, Milan, August, 2004. 
allows government to allocate seignorage intertemporally, implying that fiscal deficits, seignorage and inflation need not be contemporaneously correlated. Moreover, the short-run dynamics of the fiscal deficit-inflation relationship can be very complex.

Hence it is not surprising that no obvious short-run relationship between inflation and fiscal deficits is found for low inflation countries. Some authors claim that this relationship is more visible in transition countries where, in the absence of a developed market for government securities, fiscal deficits have to be financed by printing money. But it is not just the current deficit, but the entire future path of deficits which matters. For example, a probable increase in the government's pension liabilities in many transition economies may well result, at least in these economies, in higher deficits in the future. One must pay attention to policy changes which might be expected to affect expenditures and revenues in the future. The deficits are of concern because of the future monetary expansion they may give rise to.

In this paper I try to answer the question if there has been a positive association between fiscal deficits and inflation in several transition economies which have just become members of the European Union and intend to adopt the euro by the end of this decade. It is well known that unilateral adoption of a hard currency (in this case euroization) tends to be counterproductive unless it is supported by fiscal discipline. Analysed countries have continued to experience fiscal imbalances and fiscal pressures have been exacerbated by the electoral cycle as governments in some transition countries (the Czech Republic, Hungary and Poland) have reacted to meet near-term popular demand for fiscal profligacy, especially on the expenditure side (the so-called mandatory and quasi-mandatory outlays), neglecting the potential danger of unsustainability of public finances in the long run.

The structure of the paper is following. Section 2 discusses the theoretical underpinnings of the selected topic stressing mainly the role of both fiscal and monetary policies. Section 3 turns the attention to the data problem which is in the fiscal field far greater because only data with the annual frequency are relevant. Hence, I build first of all on descriptive statistics and the econometric results are, due to very short-time series, only tentative. Section 4 provides some preliminary conclusions and outlines the current challenges in the selected countries.

\section{Theoretical Underpinnings}

Having analysed the non-monetary determinants of inflation in a sample of industrial and transition countries, Cottarelli, Griffiths and Moghadam (1998) look at policymakers' incentives to inflate the economy. Following Cukierman they identify the revenue motive as one motive for inflationary policy. By creating seignorage the countries in fiscal troubles have a great incentive to use the inflation tax to help ease their fiscal problems.

According to the authors, the money supply will be higher, given the deficit, if government securities markets are less developed (e.g. in the transition countries).

Though this motive could explain why central banks may choose to inflate the economy, there are countervailing forces that lessen the incentive to inflate. Besides the mentioned openness of the economy we have in mind the monetary policy of central banks in the transition economies, aiming at low inflation.

Fischer, Sahay and Vegh (2002) repeat the well known statement that the usual answer to the question of what drives money growth is fiscal deficits and that inflation, in their paper more precisely, high inflation, is a fiscal phenomenon. The explanation for the creation and persistence of very high inflation which they find plausible, is that inflation initially emerges as an undesired result of fiscal imbalances 
and continues because policymakers often tend to accommodate shocks, thus allowing inflation to be driven by exogenous shocks and its own dynamics.

Their analysis shows that the relationship between the fiscal deficit and seignorage is strong only in the high inflation countries; moreover even in these countries the fiscal deficit-seignorage relationship is strengthened during periods of high inflation compared to low inflation years.

Catao and Terrones (2003) note that a well established theory in macroeconomics is that fiscally dominant governments running persistent deficits have sooner or later to finance those deficits with money creation, thus producing inflation. This "fiscal view" of inflation has been prominent in the developing country literature, which has long recognized that less efficient tax collection, political instability and more limited access to external borrowing tend to lower the relative cost of seignorage and increase dependence on the inflation tax.

They model the fiscal deficit-inflation relationship as intrinsically dynamic, explicitly distinguishing between the short run and long run. According to them, under fiscal dominance, deficits determine the present value of seignorage but not necessarily current seignorage. In their analysis for the vast majority of countries, specifications with no lagged dependent variables are rejected at conventional levels of statistical significance, indicating that dynamics is important and so that the static fixed-effects method is clearly inadequate for the task at hand. The main conclusion is similar to the results of Fischer, Sahay and Vegh - they have revealed a strong positive association between deficits and inflation among high-inflation and developing country groups, but not among low-inflation advanced economies.

Rother (2004) investigates whether activist fiscal policy has an impact on inflation volatility that raises price level uncertainty and hence exerts harmful effects on the economy.

He turns his attention to the inflationary impact of discretionary fiscal policies in both short and long run. While in the longer run monetary policies may be able to offset the short-term inflationary impact of discretionary fiscal policies, this impact may well manifest itself in short-run fluctuations of the price level, in other words inflation volatility. The offsetting effect of monetary policy may also explain why empirical studies have in many cases found only inconclusive evidence regarding the link between fiscal policies and inflation.

In his influential textbook on monetary theory C. Walsh (1998, chapter 4 entitled Money and Public Finance) raises a question if the requirement of intertemporal budget balance imposes any testable restrictions on the behaviour of government deficits. His answer stresses the lessons for the current and future behaviour of many, not only transition economies: a long sequence of primary deficits could be consistent with intertemporal budget balance as long as the government is expected to run sufficiently large primary surpluses sometime in the future.

Following the paper of Leeper (1991) Walsh distinguishes between active and passive policies. An active fiscal policy and passive monetary policy would be the one in which the monetary authority must adjust seignorage revenues to ensure intertemporal budget balance while fiscal policy does not respond to shocks. An active monetary and passive fiscal policy would be the one in which monetary policy acts to target e.g. inflation and does not respond to the government debt while fiscal policy must then adjust taxes to ensure intertemporal budget balance.

Annicchiarico (2003) illustrates how government debt and deficits might be linked to the price level dynamics in a small structural model of overlapping generations. Her analysis provides insights into the linkages between fiscal variables and the dynamics of the price level stressing the working of wealth effects. 
The main aim of her paper is to evaluate the inflationary consequences of a fiscal expansion. The government is assumed to choose a sequence of taxes according to a fiscal role that maintains a convergent path for public debt, given the monetary policy role set by an independent central bank. In her model the Ricardian equivalence condition is not satisfied.

Arratibel, Rodrígues-Palenzuela and Thimann (2002), having used the small open-economy model as an analytical benchmark, find evidence of the existence of "dual inflation" in the previous accession countries. As suggested by literature on fast-growing economies, inflation in non-tradable goods happens to be significantly higher than inflation in tradable goods in "catching-up" economies like those of accession countries.

All in all, the paper's empirical findings underline the importance of two factors for price stabilization: firstly moderate growth of nominal wages; secondly fiscal policy moderation. An increase in the government deficit ratio expands the output gap and should, therefore, have a positive impact on inflation.

In the examined field the seminal and often quoted paper is "unpleasant monetarist arithmetic" of Sargent and Wallace (1981). Their starting point is the consideration of two polar forms of coordination. In the first case monetary policy dominates fiscal policy. It means that the central bank independently sets monetary policy and determines the amount of revenue it will supply the fiscal autority through seignorage. The latter then faces the constraints imposed by the demand for bonds, since it must set its budget so that any deficits can be financed by a contribution of the seignorage chosen by the central bank and bond sales to the public.

In the second case the fiscal policy dominates monetary policy. The fiscal authority independently sets its budgets thus determining the amount of revenue that must be raised through bond sales and seignorage. Under this coordination scheme, the central bank faces the constraints imposed by the demand for government bonds, for it must try to finance with seignorage any discrepancy between the revenue demanded by the fiscal autority and the amount of bonds that can be sold to the public. If the fiscal authority's deficits cannot be financed solely by new bond sales, then the central bank is forced to create money and tolerate additional inflation.

The main gist of their analysis lies with the fact that being limited simply to dividing government debt between bonds and base money and getting no help from budget surpluses, a central bank trying to fight current inflation can only do so by holding down the growth of base money and letting the real stock of bonds held by the public grow. What is basic is their assumption, that the interest rate on bonds is greater than the dynamics of real gross domestic product (GDP). Hence, the real stock of bonds will grow faster than the size of economy. But due to the government budget constraint, this cannot go on forever, since there is an upper limit on the stock of bonds relative to the size of economy. Once that limit is reached, the principal and interest due on the bonds already sold to fight inflation must be financed, at least in part, by seignorage, requiring the creation of additional base money. In a monetarist economy, sooner or later, the result is additional inflation.

An additional assumption of Sargent and Wallace, which is important for judging the situation in transition economies, is their presentation of fiscal policy in the form of the given sequence of real government expenditures on everything except interest on government debt minus real tax collections (the real deficit less real interest payments).

Last but not least they underline, that if the central bank moves first and thereby imposes discipline on the fiscal authority, the latter is forced to choose a sequence of budget deficits consistent with the announced monetary policy. If their considera- 
tions of this kind are paramount, then the increasing deficits in transition economies are of concern because of the future monetary expansion they may give rise to.

Kopits (2002), having studied the mutual lessons in macroeconomic policy design between Central European EU Accession and Latin American Integration, stresses that unilateral adoption of a hard currency (dollarization or euroization) tends to be conterproductive unless it is supported by fiscal discipline.

Most transition economies continued to experience fiscal imbalances reflecting a weak tax base, costs associated with structural reforms, periodically eased with financing from privatization proceeds. In these circumstances, most governments have followed discretionary rather than rules-based fiscal policies.

In Latin American countries there has been typical a procyclical policy stance, often in tandem with the electoral cycle, manifested in a monetized fiscal expansion prior to elections (the deficit bias in fiscal policy and the inflation bias in monetary policy).

According to Kopits the large majority of countries in both Central Europe and Latin America remain under fiscal dominance. In his view, so far very few countries in either region (Chile and Estonia, both with the lowest public debt ratios) seem to have achieved monetary dominance. ${ }^{1)}$

The findings of Kopits corroborate conventional wisdom, namely, that fiscal discipline is essential for maintaining access to financial markets at a reasonable cost. Specifically, emerging market economies should endeavour to contain the public sector debt (including contingent liabilities) to a prudent level in relation to tax receipts, by targeting an appropriate primary surplus.

\section{Empirical Analysis}

\section{1 Descriptive Statistics}

The data in this paper stem from two sources: firstly from the Statistical Annex of the European Economy, published in spring 2004 by the European Commission, for the first time with time series for newly admitted countries (in May 2004); secondly from International Financial Statistics.

A) From the Statistical Annex of the European Economy:

Item 4, p. 37 Gross domestic product at current market prices, national currency in the cross section analysis base name (gdp);

Item 24, p. 77 Price deflator GDP at market prices, national currency, annual percentage change (inf);

Item 75, p. 174 Net lending (+) or net borrowing (-), general government, percentage of GDP at market prices (bd);

Item 76, p. 177 Net lending (+) or net borrowing (-), excluding interest, general government, percentage of GDP at market prices (pb);

Item 77, p. 178 General government consolidated gross debt, percentage of GDP at market prices (gd).

The time span is mainly from 1993 to 2003, resp. to 2005 (for 2004 and 2005 the data planned by national authorities) with some exceptions. Items 75 and 76 are for Hungary and Slovenia since 2000 only. Item 77 begins in 1997 for all countries. Data in this statistics are based on the ESA 95 system.

1) A low stock of public sector liabilities (including unfunded contingent liabilities) can be interpreted as prima facie evidence of monetary dominance. 
B) From International Financial Statistics, April 2004, or December 2000. Line 14, Reserve money ( $\mathrm{rm})$;

The sum of lines 34, Money and 35, Quasi money (ms); Line 80 , Deficit (-) or surplus (+) (ds);

Line 88, Total debt (td).

In International Financial Statistics the Deficit or Surplus ${ }^{2)}$ (line 80) is calculated as the difference between Revenue and, if applicable, Grants Received (lines 81 and $81 \mathrm{z}$ ) on the one hand and Expenditure and Lending Minus Repayments (lines 82 and 83 ) on the other. The Deficit or Surplus is also equal, with the opposite sign, to the sum of the net borrowing of the government plus the net decrease in government cash, deposits and securities held for liquidity purposes. Data for outstanding Debt (lines 88 and 89 ) relate to the direct and assumed debt of the central government and exclude loans guaranteed by the government.

The cross section identifiers are as follows: Czech Republic-CZ, Estonia-EE, Hungary-HU, Latvia-LV, Lithuania-LT, Poland-PL, Slovakia-SK, Slovenia-SI.

The associations between the inflation rate and budget deficits in 8 acceding countries in the time span 1993 - 2003 reveal that only for three countries (the Czech Republic, Hungary and Slovakia) the positive association in a calendar year exists. ${ }^{3)}$ On the contrary, in Estonia, Lithuania, Latvia, Poland and Slovenia a negative association between the inflation rate and budget deficits is evident. Basic descriptive statistics is captured in Table 1.

Table 1

Inflation Rate, Budget Deficits (1994 - 2003)

\begin{tabular}{|c|c|c|c|c|c|c|c|c|}
\hline & $\mathrm{CZ}$ & EE & $\mathrm{HU}$ & LT & LV & $\mathrm{PL}$ & SK & $\mathrm{SI}$ \\
\hline \multicolumn{9}{|c|}{ Inflation rate (in \%) } \\
\hline Mean & 7.3 & 13.9 & 14.0 & 14.0 & 10.0 & 12.8 & 6.7 & 10.5 \\
\hline Maximum & 13.4 & 39.6 & 26.7 & 61.6 & 38.3 & 37.2 & 13.4 & 22.6 \\
\hline Minimum & 1.7 & 2.7 & 5.3 & -1.2 & 1.8 & 0.7 & 4.0 & 5.1 \\
\hline Stand. dev. & 3.9 & 13.0 & 7.0 & 21.0 & 11.3 & 12.0 & 3.1 & 6.3 \\
\hline Observations & 10 & 10 & 10 & 10 & 10 & 10 & 10 & 10 \\
\hline \multicolumn{9}{|c|}{ Budget deficit (in $\%$ of GDP) } \\
\hline Mean & 6.9 & -1.2 & 5.2 & 2.3 & 1.3 & 1.9 & 8.7 & 0.6 \\
\hline Maximum & 23.4 & 2.8 & 9.3 & 5.7 & 5.3 & 4.2 & 31.2 & 1.4 \\
\hline Minimum & 1.9 & -10.2 & 3.0 & 0.8 & -2.4 & -5.4 & 0.9 & -0.4 \\
\hline Stand. dev. & 6.5 & 3.8 & 2.1 & 1.5 & 2.2 & 2.7 & 8.4 & 0.5 \\
\hline Observations & 10 & 10 & 10 & 10 & 10 & 10 & 10 & 10 \\
\hline
\end{tabular}

2) The euro area page and the pages of the individual euro area countries also present Deficit or Surplus (line $80 \mathrm{~g}$ ) and Debt (line $88 \mathrm{~g}$ ) data for the general government expressed as per cent of harmonized GDP. Both indicators are defined according to the convergence criteria on public finance as laid down in the Maastricht Treaty. Deficit or Surplus corresponds to Net Lending/Borrowing. The data are not comparable with central government Deficit or Surplus (line 80) and Debt (line 88) owing to differences in coverage as well as in definition.

3) For Hungary and Slovenia the ratios of deficit or surplus (dr) to GDP from IFS statistics are used. 
In the descriptive statistics the year 1993 has been excluded, because for Estonia the inflation rate is not given and data for other countries are extremely high due to both start of price liberalization and dissolution of the previous federal republics.

For all analysed countries the trend of disinflation is worth mentioning and in Lithuania we encounter in two years $(1999,2003)$ even a deflation. In the last year of our sample (2003) the average rate of inflation is $2.8 \%$ only, with Hungary $(5.3 \%)$ and Slovenia $(5.1 \%)$ on the one side and Lithuania $(-1.2 \%)$ and Poland $(0.7 \%)$ on the other side of spectrum. The comparison with the mean rate of inflation for the whole period $(11.1 \%)$ clearly reveals the achievements of these newcomers to the European Union in the last decade.

As concerns the budget deficits the picture is more complicated showing increasing deficits in last years in the Czech Republic, Hungary, Poland and Slovenia. An exemplary performance displays Estonia with budgetary surpluses in the majority of years, first of all in the last three years. The performance of other Baltic countries is also remarkable.

The descriptive statistics show that a certain positive association between yearly data on the inflation rate and budget deficits can be discovered in a small sample of three countries only - the Czech Republic, Hungary and Slovakia. The remaining Visegrad country - Poland shows a negative association and from the pool sample must be excluded.

\section{2 Econometric Analysis}

Each country has its own base level of the inflation rate, hence the equation should have a different intercept for each country (fixed effect model). Specific intercepts can absorb any permanent differences across countries. Seemingly unrelated regressions (SURE) have been used (E-Views, 4.1).

The budget deficits as an explanatory variable are statistically significant in the first three equations with $P$-values $0.036,0.01$ and 0.014 , respectively. In these

Table 2

Pilot Estimates (SURE, 1993 - 2003)

\begin{tabular}{|c|c|c|c|c|c|c|c|}
\hline Dep. var.: inflation & 1 & 2 & 3 & 4 & 5 & 6 & 7 \\
\hline Budget deficit & $\begin{array}{c}0.22 \\
(2.24)\end{array}$ & $\begin{array}{c}0.26 \\
(2.98)\end{array}$ & $\begin{array}{c}0.23 \\
(2.69)\end{array}$ & & & & \\
\hline Budget deficit $(-1)$ & & & & & & & $\begin{array}{c}0.21 \\
(2.97)\end{array}$ \\
\hline Money supply & & $\begin{array}{c}-0.60 \\
(-2.63)\end{array}$ & & & & & \\
\hline Reserve money & & & $\begin{array}{c}-1.10 \\
(-3.60)\end{array}$ & & $\begin{array}{c}-1.14 \\
(-3.69)\end{array}$ & & \\
\hline Primary balance & & & & $\begin{array}{c}0.21 \\
(2.15)\end{array}$ & $\begin{array}{c}0.22 \\
(2.58)\end{array}$ & & \\
\hline $\begin{array}{l}\Delta \text { Government } \\
\text { debt }\end{array}$ & & & & & & $\begin{array}{c}0.15 \\
(2.14)\end{array}$ & \\
\hline$N$ & 26 & 26 & 24 & 26 & 24 & 18 & 23 \\
\hline$R^{2}$ & 0.25 & 0.30 & 0.64 & 0.24 & 0.63 & 0.26 & 0.26 \\
\hline
\end{tabular}

Note: $t$-values in brackets. 
equations the results say that a one percentage point increase in budget deficits is associated with a $0.22-0.26$ percentage point increase in the inflation rate. If we lag the budget deficits one year (eq. 7) the results are similar with better $t$-statistic $(P=0.008)$. The highest coefficients of determination are in equations 3 and 5 , where the reserve money has been included. This variable is significant, but with the wrong sign.

The equations with the primary balance, instead of budget balance, give similar results (the reason is that the interest costs in both the Czech Republic and Slovakia were in this time span almost constant as ratios to GDP). The change of government debt does not improve the picture (eq. 6) with a very small number of observations.

The relation between inflation and seignorage ${ }^{4)}$ shows a positive association (but statistically insignificant) in the Czech Republic and Slovakia, but a negative association in both Hungary and Poland. Hence the introduction of seignorage as cross section specific coefficients in the above mentioned panel of three countries increases the coefficient of determination (0.34), the coefficients have a good sign (plus), but are statistically insignificant.

If we use planned figures of national authorities for 2004 and 2005 to increase the number of observations (inflation, budget deficits), the results are a bit better (see Table 3).

Table 3

Additional Estimates (SURE, 1993 - 2005)

\begin{tabular}{|l|c|c|}
\hline Dep. var.: inflation & 1 & 2 \\
\hline Budget deficit & 0.18 & \\
& $(2.31)$ & 0.19 \\
\hline Budget deficit $(-1)$ & & $(3.36)$ \\
\hline$N$ & 39 & 36 \\
\hline$R^{2}$ & 0.29 & 0.33 \\
\hline
\end{tabular}

\section{Preliminary Conclusions and Current Challenges}

\section{1 Preliminary Conclusions}

Putting aside the differences in both the methodological approach and chosen data set I cannot confirm some results of the above mentioned authors as concerns the transition countries. Cottarelli, Griffiths and Moghadam (1998), having analysed 47 industrial and transition economies during 1993 - 1996 (22 industrialized OECD countries, 10 countries from Central and Eastern Europe and 15 countries from the former Soviet Union), are particularly interested in comparing the experience of transition economies with that of industrialized countries. In the Table 3, p. 23, showing the results for the transition country group (75 observations for 25 countries), they claim significantly better fit than for the whole sample. According to them: "...the

4) "Seignorage is defined as the ratio of the difference between reserve money at the end and beginning of the year to GDP in this year" (Fischer, Sahay, Vegh, 2002, p. 29). 
correlation between inflation and the fiscal balance is stronger for transition economies“ (pp. 15-16).

In the final part of the paper they assert: "The results fit better for the transition country group, possibly because of the higher variation of the data in this group... Overall, they support the view that fiscal policy has a significant effect on inflation, particularly in countries where government securities markets are less developed. However, there is evidence of a relation between inflation and fiscal deficits also in other countries" (p. 24).

Fischer, Sahay and Vegh (2002) examined 133 market economies in the horizon $1960-1996$. Their results are as follows: "When annual panels are considered, the relationship between the fiscal balance and inflation becomes significant for the high inflation countries but not for the low inflation countries" (p. 31). And even more subtle conclusion: "...the relationship between inflation and the fiscal balance is significant for high inflation episodes but not for low inflation episodes“ (p. 31).

Also Arratibel, Rodrígues-Palenzuela and Thimann (2002), in a paper devoted to the analysis of accession countries, indicate the link between fiscal policy and inflation in these countries: "tradable inflation has been particularly affected by oil price, nominal wage growth and fiscal developments, whereas non-tradable inflation has been mainly imparted by wage and fiscal policy, price liberalization and productivity developments...In sum, the paper's empirical findings underline the importance of nominal wage moderation and fiscal policy consolidation for price stabilization, as well as the impact of liberalization-oriented reforms on lowering inflation, particularly in the non-tradable sector"( p. 5).

Very broad and up-to-date dataset (107 countries, the horizon $1960-2001)$ is analysed in the paper of Catao and Terrones (2003). But the analysis is limited on the countries for which exist no less than 20 years of continuous annual observations for the 4 variables featuring their theoretical model, i.e. inflation, the budget balance, GDP and narrow money. In the sample of emerging markets they mention the Czech Republic, Hungary and Poland in spite of the fact that these countries cannot fulfil the assumption of required number of annual observations. The conclusions are in favour of significant budgetary impacts on inflation: "...fiscal deficits continue to display a powerful effect on inflation in developing countries, emerging markets and high-inflation economies and a much smaller effect amongst moderate inflation countries" (p. 18).

Last but not least it has to be mentioned the partial conclusion of Rother (2004) who, having surveyed the papers of his predecessors, asserts: "The empirical support for a causal relationship between the level of fiscal deficits and inflation through the monetary channel is somewhat mixed" (p. 9).

After the enumeration of results of some relevant papers and their confrontation with our tentative conclusions one must think over the links between fiscal policies and inflation in previous transitive, nowadays new EU countries of Central and Eastern Europe. What emanates from the literature is following:

a) government demand on goods and services is a part of total macroeconomic demand. Hence an increase in the government deficit ratio expands the output gap and should, therefore, have a positive impact on inflation. What is further important is the algebra of budget deficits (see the seminal contribution of Sargent and Wallace and their analysis of the situation when the interest rate on bonds is greater than the growth rate of real GDP);

b) the revenue motive - to use the inflation tax to help ease the fiscal problems is at variance with the monetary policy of the central banks aiming at low inflation. The offsetting effect of monetary policy may also explain why empirical studies have 
in many cases found only inconclusive evidence regarding the link between fiscal policies and inflation;

c) what is crucial is the distinction between two polar forms of coordination: the dominance of monetary policy implies that the central bank independently sets monetary policy and determines the amount of revenue that will supply the fiscal authority through seignorage. The dominance of fiscal policy implies that the fiscal authority independently sets its budgets thus determining the amount of revenue that must be raised through bond sales and seignorage.

Hence, fiscal deficits necessarily imply that inflation will eventually occur in a situation of fiscal dominance only. With fiscal dominance, an increase in government debt will eventually require an increase in seignorage. In other words, fiscal policy must be active and monetary policy passive. In this constellation monetary authority must adjust seignorage revenues to ensure intertemporal budget balance. On the contrary an active monetary and passive fiscal policy would be the one in which monetary policy acts to target e.g. inflation and does not respond to the government debt while fiscal policy must then adjust taxes to ensure intertemporal budget balance. So if the central bank imposes discipline on the fiscal authority, the latter is forced to choose a sequence of budget deficits consistent with the announced monetary policy. This is the situation more relevant for the new EU Members. ${ }^{5}$ By the way fiscal discipline is essential for maintaining access to financial markets at a reasonable cost. New EU Members should endeavour to contain the public sector debt (including contingent liabilities) to a prudent level in relation to tax receipts, by targeting an appropriate primary surplus;

d) as concerns the technical aspects it must be stressed that the relationship fiscal deficit inflation is intrinsically dynamic, explicitly distinguishing between the short run and long run. Dynamics is important and, one must admit, the static fixedeffects method used in our econometric analysis, is not adequate for the task at hand.

\section{2 Current Challenges}

Accession to the European Union in May 2004 marks the completion of transition for the previous command-type economies, but also reminds of economic challenges ahead. The focus of policies is now on furthering catch-up to EU income levels in the longer time horizon and adopting the euro in the horizon of several years. What is for this paper more important is the fact that currently worsening fiscal situation in the Visegrad countries poses one of the most demanding tasks for macroeconomic policy, hence an analysis of the current policy stance in these countries is needed. The results of the IMF's missions in the Visegrad countries and the other sources stress the following findings.

\section{The Czech Republic}

The general government deficit widened above 6 per cent of GDP in the last years, primarily reflecting upward drift in mandatory spending (mandatory and quasi-mandatory spending represent around $80 \%$ of all current expenditures). General government consolidated gross debt continues to climb - the outlook for 2004 and

5) We cannot agree with G. Kopits that monetary dominance exists in this country sample in Estonia only. 
2005 is more than $40 \%$ of GDP - the "graduation" to a moderate debt level, only due to very low levels in the mid 1990s.

In spite of large privatization receipts this upward trend, markable since 2000, presents great danger for the continuation of successful monetary policy. Let us remind that one way to generate a required surplus is to increase revenues from seignorage and that for that reason economists have been interested in the implications of budget deficits for future money growth. The mechanism, under the regime of fiscal dominance, is straightforward; by lowering current inflation tax revenues the deficit grows and the stock of debt rises. A larger debt implies an increase in the present discounted value of future tax revenues, including revenues from seignorage. If the fiscal authority does not adjust (the contemporary crossroad in many new EU Members), the monetary authority will be forced eventually into producing higher inflation.

The philosophy of Czech transformation - residual obligations from bank and enterprise restructuring and the granting of state guarantees is only a partial culprit of disturbing upward trend in public indebtedness. The Achilles heel of the Czech transformation on the road to a full-fledged market economy still represent the needed structural reforms. Especially in such crucial areas as pension and health care reform, progress is slow or has stalled. Prompt reforms to slow the growth of pension and health care spending can be brought to a standstill in the situation of government crisis (end of June 2004) and potential social unrests. At least significant changes to pension system parameters are badly needed, forging required social consensus on the necessity and nature of the reforms with their intergenerational impacts.

The inflation targeting framework (since January 1997) represents a sound anchor for monetary policy during the pre-euro period and excludes, de facto, the fiscal dominance. Responsibility for meeting the ambitious goals in the field of monetary policy lies of course not just with the Czech National Bank; credibility of the strategy depends also on the behaviour of fiscal authorities. Hence, placing the fiscal deficit on a downward path belongs to the most urgent priorities.

In the framework of internal stability pact, closer coordination between the central, regional and municipal governments is needed to ensure that all levels continue to the adjustment effort.

The government budgetary plan tries to reverse the unfavourable trends within a multi-year framework. The plan is formulated in an explicit medium-term framework with a rolling 3-year horizon and with the added discipline of expenditure ceilings. Annual state budgets and policies with multi-year implications should conform to this medium-term framework, giving a high degree of predictability to fiscal policy. The development in the near future will show to what a degree these promises are wishful thinking only and what type of monetary-fiscal coordination will be chosen.

\section{Hungary}

Hungary faces similar challenges over the next few years as the Czech Republic. On the one side it must support continued economic growth, on the other side it must realize significant fiscal adjustment (see the increasing deficit/GDP ratio and the general government consolidated gross debt hovering around $60 \%$ of GDP in the examined period).

Dealing with macroeconomic imbalances and re-establishing policy credibility have been the most pressing issues on the road to euro adoption. There is general agreement that large fiscal and current account deficits would impair future macroeconomic development. Moreover, the loss of policy credibility would make the fi- 
nancing of these twin deficits all the more precarious. Thus, without action, Hungary would be vulnerable to significant exchange rate and interest risks in the period immediately ahead and, maybe, more evident fiscal dominance in the future.

Hungary also plan to introduce 3-year rolling expenditure ceilings to serve as a basis for medium-term budget planning and to move towards performance-based budgeting in order to strengthen fiscal management. With respect to the medium term the Hungarian authorities realise the importance of fiscal consolidation at the current critical juncture. There is a consensus that taking decisive actions in support of fiscal adjustment is the only way to restore policy credibility and improve the monetary-fiscal policy mix. Significant tightening would allow risk premia and interest rates to come down and limit vulnerability of shifts in market sentiment.

Important measures, firmed up in February 2004, come from reducing ministries' operational spending; from restraining transfers from the ministries to institutions under their control and from scaling back project and investment spending.

The progress so far with structural fiscal reforms recommended by the international organizations in recent years has been, as in the Czech Republic, limited. While difficult politically, further fiscal consolidation is required in the medium term and would be especially beneficial if concentrated on expenditure restraint. This reflects the already high taxation, particularly on labour. At the same time, to leave room for spending pressures arising from public investment needs and EU accession, careful expenditure prioritization will be needed while focusing on consolidating current expenditure.

As in other European countries the potential benefits of increasing the labour force participation rate, including by leaving room for labour tax cuts and reducing disincentives to work stemming from the structure of benefits, could be to raise potential output and help mitigate pressures on public finances in the foreseeable future.

The above mentioned 3-year rolling framework including a ceiling on overall expenditure and sub-ceilings on key components should contribute to enhancing fiscal performance and credibility. Such a framework should be submitted to Parliament with a clear statement of policy as part of the budgetary process.

\section{Poland}

Poland belongs to a group of new EU Members with deteriorating fiscal performance and with the ratio of general government debt to GDP approaching the level of $50 \%$. This will put continued pressures on public finances in the coming years. Hence the question of fiscal sustainability in the future ought to be answered.

According to some estimates, even if the present output gap is fully eliminated by 2008 , unchanged fiscal policies and the budgetary impact of EU accession are projected to lead to an increase in public debt relative to GDP to about $70 \%$ in 2013. Under this scenario, public debt would surpass the Constitutional limit of $60 \%$ of GDP in 2007.6)

6) Poland is unique among the EU accession countries because it has a Constitutional limit on public debt, 60 per cent of GDP and a set of supporting procedures, stipulated in the Public Finance Act (PFA), that are aimed at capping the increase in the public debt-to-GDP ratio before it reaches $60 \%$. The debt limit and the supporting procedures embedded in the Constitution and the PFA are more stringent than the Maastricht debt reference value (see IMF Country Report, 2003, p. 6-7). 
Exposure to fiscal risks is significant and it is likely to increase in the future if fiscal policy remains unchanged. In determining the sustainability and gauging the vulnerability of fiscal policies, three major groups of fiscal risks in Poland are being considered: a) macroeconomic risks; b) refinancing risks; c) risks stemming from contingent liabilities.

Ad a) These risks stem from changes in growth, the exchange rate and interest rates. More precisely one speaks about fiscal risks stemming from fluctuation in growth, which is higher than in most euro area countries. Two negative growth shocks (2001 - 2003 and probably 2005 - 2007) could raise general government deficit above $10 \%$ of GDP by 2007 . It suggests the magnitude of the vulnerability of public finances to a negative growth shock. The budget is also vulnerable to exchange rate and interest rate shocks although to a lesser extent. By reducing the share of foreign debt in total debt Poland significantly reduced the exposure of the budget to exchange rate risk. The impact of an increase in domestic interest rates would be considerably stronger than that of nominal depreciation.

Ad b) As public debt continues to increase under unchanged policies, gross borrowing requirement also reaches higher levels. It is projected to be close to $70 \%$ of total revenue by 2004 , compared to $34 \%$ in 2001 . This means that even a short period of market turbulence could pose a threat to public finances and eventually to macroeconomic stability, unless the government keeps sufficiently large liquid reserves.

Ad c) Contingent liablities of the budget are also a potential threat to the stability of public finances both in Poland and the Czech Republic. At the end of 2002, outstanding state treasury guarantees were $4.2 \%$ of GDP. The risk weighted stock of outstanding guarantees is included in public debt (adding some $1.6 \%$ of GDP to public debt at the end of 2002). Nonetheless, a rapidly increasing stock of outstanding guarantees will inevitably increase the risk the state budget will have to undertake. This risk is not necessarily reflected in current deficit measures, as the allocation for expected payments on called guarantees in the budget bears no direct relationship to the risk-weighted stock of outstanding guarantees included in the general government debt.

Last but not least, an important source of contingent liabilities are large, financially weak state-owned enterprises. Some of the borrowing of these enterprises has already been guaranteed by the Ministry of Finance and, thus, is accounted for in the general government debt. Though the current fiscal stance is not unsustainable in a technical sense, reducing fiscal vulnerability, as well as complying with the Constitutional limit on debt and meeting the Maastricht criteria will require a major fiscal asjustment. But without a well designed package of structural fiscal, mainly mandatory expenditure, reforms, ad hoc attempts to comply with the law are likely to be unsustainable in the longer run. Moreover, most structural expenditure reforms need time to produce sizable savings.

\section{Slovakia}

Slovakia seems to be in a better fiscal position than its Visegrad neighbours. It has been proven by the declining trend in both budget deficit and general government debt ratio since the year 2000 . This country can only benefit from staying the course with bold policies that have served it so well in past years. The main challenge now is to pursue a policy mix that will lead to a sustainable fiscal position and disinflation. Such a policy together with the completion of the unfinished structural reform agenda - particularly in the areas of health care, education, legal framework and devolution of fiscal responsibilities - would reinforce good economic prospects. 
Fiscal tightening (especially indirect tax and administered price increases) and the associated fall in real wages dampened private sector consumption. Continued fiscal consolidation is needed in the coming years to make room for higher private investment and also to maintain the external account deficit within sustainable limits.

The budgeted deficit for 2004 (4\% of GDP) is well within reach and should be met with a considerable margin, assuming no new unbudgeted expenditures. The government also, as its neighbours, prepares for the first time a 3-year budget framework, which could give a higher degree of predictability to fiscal policy and strengthen its credibility. This framework is also a vehicle to bring together a critical mass of reforms envisaged by the government or already underway.

The welfare reform to rationalise benefits and improve incentives for job search and employment creation contributes to the envisaged restructuring of expenditures. Continued health sector reform and the planned pension reform are also essentials for medium- and long-term sustainability of public finance.

Projections of deficit targets will require the full implementation of difficult envisaged expenditure policies. The approved 3 years' budget framework implies a reduction of one percentage point of GDP in revenues in 2007, primarily reflecting revenue losses from the first pillar of the pension system, as pension reform takes effect. Slovakia's Convergence Programme is very ambitious, it envisages achieving fiscal balance by 2010 . Such a strenghtening of the fiscal position would help keep general government debt at a moderate level between $40 \%$ and $50 \%$ of GDP.

\section{References}

Annichiarico, B. (2003), "Government Deficits, Wealth Effects and the Price Level in an Optimizing Model“. Frankfurt/M, European Central Bank, WP No. 285.

Arratibel, O., Rodríguez-Palenzuela, D. ,Thimann, Ch. (2002), "Inflation Dynamics and Dual Inflation in Accession Countries: A ,New Keynesian' Perspective“. Frankfurt/M, European Central Bank, WP No. 132.

Catao, L., Terrones, M. E. (2003), "Fiscal Deficits and Inflation“. Washington, IMF, WP/03/65.

Cottarelli, C., Griffiths, M., Moghadam, R. (1998)," The Non-monetary Determinants of Inflation: A Panel Data Study“. Washington, IMF, WP/98/23.

Fischer, S., Sahay, R., Vegh, C. (2002), "Modern Hyper and High Inflations". Washington, IMF, WP/ 02/197.

IMF (2004), "Czech Republic: Consultation Mission Preliminary Conclusions". Washington, International Monetary Fund, May.

(2004), "Czech Republic: Selected Issues and Statistical Appendix". Washington, Country Report No. 04/3.

(2003), "Hungary: Selected Issues“. Washington, Country Report No. 03/125.

(2004), "Hungary". Washington, Country Report No. 04/145.

(2004), "International Financial Statistics". Washington, April.

(2003), "Republic of Poland: Selected Issues". Washington, Country Report No. 03/188.

(2003), "Slovak Republic". Washington, Country Report No. 03/235.

Kopits, G. (2002), "Central European EU Accession and Latin American Integration: Mutual Lessons in Macroeconomic Policy Design“. Oesterreichische Nationalbank, WP 75.

Rother, P. (2004), "Fiscal Policy and Inflation Volatility“. Frankfurt/M, European Central Bank, WP No. 317.

Sargent, T., Wallace, N. (1981), "Some Unpleasant Monetarist Arithmetic". Federal Reserve Bank of Minneapolis Quarterly Review, 5 (3), Fall, pp. 1-17.

Statistical Annex of European Economy (2004). Brussels, European Commission, ECFIN/174/ 2004.

Walsh, C. (1998), Monetary Theory and Policy. Cambridge, MA: The MIT Press. 